thus exist stars far more dense than any material yet known to us. This may be the key to a puzzle presented by the companion of Sirius and a few other stars known as "white dwarfs"; the newly discovered companion of Mira Ceti is (according to preliminary accounts) another example. The faint companion of Sirius is classed as of spectral type $F$; if this means that it has the surface-brightness ordinarily associated with type $\mathrm{F}$, its radius is about 20,000 kilometreswhich seems absurdly small for a star. Its mass is well-determined and is about $\frac{4}{5}$ that of the sun. The resulting mean density is $50,000 \mathrm{gm}$. per c.c. This conclusion has probably been regarded hitherto as a reductio ad absurdum, showing that the star must manage in a mysterious way to produce the $\mathrm{F}$ type of spectrum without the intensity of radiation ordinarily required for it. But the deduced density cannot now be considered impossible, and the companion of Sirius may be an actual example of the high density attainable by matter when ionised by the enormous temperature in a star. Fortunately it will be possible to test whether this is so by determining the Einstein shift of the spectral lines, which would be large enough to be measured if the high density is correct. If the result of the test should prove favourable and establish the existence of matter having density of the order 50,000 , we shall have fewer qualms in accepting perfect gases of the density of platinum.

\title{
Electrical Exhibits at the British Empire Exhibition.
}

THE greater part of the exhibits of electrical interest in the British Empire Exhibition at Wembley Park is concentrated in the great Palace of Engineering, which, during these early weeks of the Exhibition, is one of the most complete portions-and perhaps the most imposing-of the whole stupendous display. The electrical engineering section, which was organised by the British Electrical and Allied Manufacturers' Association, in conjunction, as regards certain sections, with the Electrical Development Association and the Cable Makers' Association, covers no less than $4 \frac{1}{2}$ acres of the vast building, forming, we believe, the largest single section of the Exhibition and probably the most complete collection of modern electrical engineering plant and apparatus that has yet been brought together. It is concentrated in one end of the building, and provided with entrances named appropriately after Faraday and Kelvin.

An important feature of the heavy electrical plant is the complete generating station, used to supply power to the Exhibition, with fully equipped boiler-house, turbo-generators, switchgear, transformers, etc., representing some 6000 h.p., all in full view of visitors. Generating plant, on a large scale driven by turbines, reciprocating steam engines, and internal combustion engines, is also represented on the stands of practically all the well-known British makers of such plant. We do not propose to refer here to more than two or three examples of the exhibits of those firms the names of which are household words to every electrical engineer, including, besides those mentioned below, such firms as the English Electric Co., Ltd., the MetropolitanVickers Electrical Co., Ltd., the General Electric Co., Ltd., the Brush Electrical Engineering Co., Ltd., Crompton and Co., Ltd., Bruce Peebles and Co., Ltd., Mather and Platt, Ltd., the British Electric Transformer Co., Ltd., Electromotors, Ltd., and many others.

From the steam side, one of the most interesting of these exhibits is the $12,000 \mathrm{kw}$. turbo-generator of the latest type of C. A. Parsons and Co., Ltd., marking the culmination of many years of development in generating plant. From the point of view of hydroelectric power development, an outstanding exhibit is a 30,000 h.p. twin impulse turbine to run at 375 r.p.m. under a head of $1630 \mathrm{ft}$., with the Seewar patent governing device shown in action by means of a separate, electrically driven oil-pump, forming part of the comprehensive display of the English Electric Co., Ltd. Five such turbines are now in course of manufacture for India. An interesting exhibit on the purely electrical side is the display of a complete, automatically controlled, $500 \mathrm{kw}$. rotary converter substation on the large stand of the British Thomson-Houston Co., Ltd. This exemplifies a modern tendency much on the increase, particularly in high-tension D.C. railway working. Another sign of recent developments, relating, however, more to overseas conditions than to those at home, is the presence of apparatus for outdoor substations and switch-points of very high tension transmission lines. Here it is interesting to note that Electric Control, Ltd., has provided an alternative to the usual oil-break apparatus in air-break switches for voltages up to I 30,000 volts. This firm also shows air-break fuses for overhead open-air positions for such high voltages, and an interesting fuse, enclosed in a glass tube filled with carbon tetrachloride, which immediately extinguishes the arc without the glass tube breaking. Modern developments in another direction, that of power-factor compensation, are exemplified in the display by British Insulated and Helsby Cables, Ltd., of electrostatic condensers for this purpose, capable of dealing with as much as $300 \mathrm{kva}$. in one unit.

The two principal large exhibits relating to electric traction are a train exhibited by the Metropolitan Railway in the Palace of Engineering and the electric locomotive attached to the South African train in another part of the grounds. Electric working in collieries, including a complete winding plant, will be found in operation in the model coal mine. These features we have not space to describe here.

Switchgear and motor control gear are exhibited by firms too numerous to particularise. Perhaps the finest display of this kind is that of iron-clad switchgear by Reyrolle and Co. Turning from large to small apparatus, a very convenient type of commutating rectifier may be mentioned on the stand of the Lancashire Dynamo and Motor Co., Ltd., associated with the Crypto Electrical Co., Ltd. This is for charging small accumulators, running cinema arc lamps, or other D.C. apparatus from A.C. circuits, and comprises, all in one compact little machine, a transformer and a synchronous motor, with an external commutator provided with suitable brush gear and arranged with a self-starting

No. 2848 , voL. I I 3$]$ 
device needing only the closing of a single switch. The cable industry is represented by a fine combined exhibit organised by the Cable Makers' Association, and it is interesting to see on the stand of Callendar's Cable and Construction Co., Ltd., cables and accessories for pressures up to 66,000 volts. Domestic applications of electricity are demonstrated by a well-arranged combined exhibit under the auspices of the Electrical Development Association.

Practically all the well-known incandescent lamp makers are represented, and a glance at their exhibits shows how the gas-filled tungsten lamp is supplanting all other forms of electric lighting except for special purposes. Particular attention should be directed in this connexion to the lamps in special bluish glass bulbs giving, by selective absorption, the nearest possible approximation to daylight for colour-matching, picturelighting, etc. It may be remarked here that these are used with quite remarkable results in the artificially lighted tanks, etc., in the new aquarium of the Zoological Society. Among lamps for special purposes, a complete range of "Pointolite" lamps, in which a minute but brilliant arc is produced between tungsten electrodes in a glass bulb, is shown on the stand of the Edison and Swan Electric Co., Ltd. These lamps, which are specially valuable for small projector and other focus work, now range from 30 to rooo c.p.

Measuring instruments, both of the switchboard and portable types, are shown by such well-known firms as Evershed and Vignoles, Ltd., Elliot Brothers, Ltd., and Everett Edgecumbe and Co., Ltd. Special features of the stand of the last mentioned are the display of synchronising apparatus and portable photometers. Another instrument display of interest is that of the Cambridge Instrument Co., Ltd. Here is shown a new pattern of metal cased recorder for carbon dioxide and temperature records, with which several records can be made on one drum, and a recent pattern of carbon monoxide recorder, in which the carbon dioxide in the gases to be tested is first removed by an electrically heated catalyst. Another new instrument is a substantially constructed distance thermometer with multiple contact switch, whereby temperature readings can be taken on the same instrument from as many as 72 distant points. The firm also shows the electrically worked Thomson gas-meter, particularly suited to large capacities, which measures the gas flowing through the meter by warming it with an electric heater by a fixed amount adjusted by the balance between entrance and exit thermometer resistances, forming arms of a Wheatstone's bridge, and measuring the amount of energy required. Mains testing sets of a very complete form are also shown. Another stand, largely devoted to electrical temperature measurement, is that of the Foster Instrument Co. Direct reading thermo-couple and resistance thermometers are included together with an interesting pattern of optical pyrometer, in which the filament of a lamp is viewed in the field of a telescope directed to the hot body and the current through it adjusted until the filament is invisible. This filament forms one arm of a Wheatstone's bridge, and the variation of its resistance controls the current in a milliammeter in the galvanometer circuit attached to the instrument, which is graduated so that temperature can be read directly. A radiation pyrometer, in which the rays from the hot body are focussed on to a thermo-couple, is also shown.

A considerable section, involving some striking exhibits, is devoted to telegraphy and telephony. The methods of ordinary land telegraphy can be studied in the special display by the British Post Office in the fine building housing all the official exhibits of the British Government. Here is exemplified high-speed Wheatstone automatic working, land line repeater stations, Baudot multiplex printing telegraphapparatus, and many other standard systems in everyday use. A variety of telegraph instruments can also be seen on the stand of Elliot Brothers, Ltd., in the Palace of Engineering.

In the field of cable telegraphy one of the most interesting and complete displays is that of the Eastern Associated Telegraph Cos. This includes a working demonstration of the apparatus employed on a long cable route with one intermediate station. Starting from the transmitting end we have the latest pattern of keyboard perforator, the paper strip from which, punched in the ordinary code, is passed to a new pattern of motor-driven transmitter with a magnetic tongue arrangement, causing the moving contact to remain over on whichever side it has been moved by the mechanical action controlled by the peckers, until the next movement. At the intermediate station the feeble signal currents received from the cable are first dealt with by a jockey relay of the moving coil type, automatically corrected for stray earth currents by an arrangement analogous to a shifting zero, in which the "fixed" contacts are caused to drift or change their position according to the earth currents. In this instrument, owing to the sluggishness of the cable, the "dots" are practically lost, but the action of the next piece of apparatus, a Gulstad relay coupled to the jockey relay by a bridge connexion, is to interpolate the dots again. The signal currents thus produced are passed to a "translator" of similar construction to the P.O. pattern of relay, which acts as a transmitter to the second length of cable. This is supposed to be of greater length than the first section, and therefore an electrolytic magnifier is used at the terminal receiving station as well as the jockey and Gulstad relays, from which the current impulses pass to a P.O. relay which feeds a Creed electro-pneumatic receiving perforator of a pattern fitted with a special correcting device ensuring isochronous working. The punched strip from this instrument is passed through a Creed type printing apparatus of the pattern described in NATURE (December 9, I920, p. 472), whence the message finally emerges in printed characters. Other interesting items on this large stand include a big map of the Companies' cable routes throughout the world, any section of any cable route on which can be illuminated from behind by neon tube lamps bent to follow the positions of the cables.

Among historic instruments is a Kelvin siphon recorder dating from 1877 , by the side of the latest form of this type of instrument; an early speaking galvanometer is also shown. A number of samples of cables made by the Telegraph Construction and Maintenance Co., Ltd., are shown, ranging from pieces of the first submarine telegraph cable laid between Dover and Calais in $185 \mathrm{I}$, and picked up fifty-six years later, to a modern

NO. 2848 , vOL. I I 3$]$ 
cable in which continuous inductive loading is supplied by an iron-nickel strip lapped round the conductor. A number of models of old and new cable ships are shown, and several items of their equipment, including a deep-sea sounding machine and the latest form of grapnel used for picking up cables, are exhibited. Another fine display, not, however, so complete at the time of our visit, is made by the Pacific Cable Board. Submarine cables of a considerable number of patterns are also shown by Siemens Brothers and Co., Ltd. Of particular interest are those provided with brass tape protection against the ravages of the Teredo; the possible extent of which is shown by interesting samples of cables damaged by the ship-worm. The Company is also exhibiting a variety of telephone cables including paper-insulated cables for land telephone lines, containing as many as rooo pairs, and a four-core loaded submarine telephone cable cut open at a loading point to show the four Pupin coils, one for each core, side by side.

In the domain of telephony generally, the exhibits are too numerous to particularise. Of special interest are the displays of apparatus for automatic exchange working, forming part not only of the G.P.O. exhibit in the British Government building, but also on various stands in the Palace of Engineering, where the differences in the methods of working of the Strowger, Siemens, Western Electric, Relay, and other systems can be compared.

Attention should also be directed to the demonstration of up-to-date features of long-distance telephony on the stand of the Western Electric Co., Ltd., including loading coils for land lines and a full working example of a telephone repeater station. Loud-speaking telephones are shown on several stands, including the wellknown apparatus of Alfred Graham and Co., Ltd., and a particularly effective system known as the electromegaphone, shown by S. G. Brown, Ltd., the principal feature of which is the use of a compound differential microphone, in which the increase of pressure on one side of the element attached to the diaphragm and the decrease of pressure on the other are both made use of. Another special type of telephone is shown on the large and varied stand of the Telephone Manufacturing Co. in the now well-known laryngophone, in which a pad pressed against the side of the throat takes up the voice vibrations, and much extraneous noise is eliminated.

A great deal of interest will be aroused by the fine and varied exhibits of wireless telegraph and telephone apparatus, probably the most complete collection of modern apparatus of this nature ever brought together. It is only possible here to direct attention to a few of its more notable features. The foundation of practically all modern developments is the thermionic valve, and very appropriately Prof. J. A. Fleming, to whom its use for wireless telegraph purposes was originally due, has arranged in the British Government Pavilion a collection of about fifty typical valves with admirable descriptive labels tracing the history and development of the use of this class of apparatus. The valves shown range from the original experimental valves used by Prof. Fleming as rectifiers in 1904, and others soon following used as wireless detectors, to high-power transmitting valves in glass bulbs up to 600 watts and in silica bulbs up to 2500 watts used with anode voltages ranging up to $x 2,000$ volts. Many types of amplifier valve are shown and special four-electrode valves, as well as the latest developments in "dull emitter" valves permitting of great economy in filament current consumption by the incorporation of thorium into the filament during manufacture. One stand in the Palace of Engineering, that of the Mullard Radio Valve Co., Ltd., is entirely devoted to valves, and here also large silica transmitting valves are to be seen. Another valve exhibit is that of the Marconi Osram Valve Co., forming part of the display of the General Electric Co., Ltd., and its allied concerns. It has hitherto been usual to employ multicell dry batteries for the anode circuit of receiving valves, but it is interesting to observe on the stand of several of the accumulator makers compact multicell accumulator batteries for this purpose. Attention may also be directed to a very successful attempt to avoid the use of valves and their paraphernalia altogether in small sets in the "Crystavox" of S. G. Brown, Ltd., in which a loud speaker is combined with a self-contained microphone amplifier. This enables a loud speaker to be added to any ordinary crystal set without the use of valves.

The largest stand devoted exclusively to wireless apparatus is that of the Marconi's Wireless Telegraph Co., Ltd., and its associated companies. In the centre are two large $80 \mathrm{kw}$. valve transmitting equipments built up of units and employing $x 6$ valves in parallel each, such as have been used together for direct experimental communication with Australia, and of the same type as proposed for the Imperial Wireless chain stations. A complete $6 \mathrm{kw}$. valve transmitting equipment for broadcasting, a duplicate of that employed at the London Broadcasting Station, 2 LO., is shown, and an example of the new electro-magnetic "microphone " used with such success at the London broadcasting studio and elsewhere. In this instrument a variable E.M.F. is induced in an aluminium ring caused to vibrate in a powerful magnetic field, and the fact that the E.M.F. produced is inversely proportional to the frequency is corrected by an inductioncapacity arrangement in the circuit of the first amplifying valve, by which the voltage fed to the next valve varies directly as the frequency. Wireless sets for special purposes include ship sets, lifeboat sets, and a very compact trench set with a short aerial not projecting above the parapet with a range of about 5 miles. There is also a most interesting collection of aircraft wireless telephone apparatus, including specially light and durable aeroplane sets and aerodrome ground station equipment arranged for switching through to exchange lines, so that any subscriber can communicate with a machine in the air. The Marconi V.4 set for broadcasting reception may be described as a good example of such apparatus with modern refinements. This is arranged in a convenient cabinet, and can be worked on wave-lengths from 300 to 3300 metres without any exchange of coils. The upper panel contains equipment for a two-valve reflex set (i.e. with one of the valves performing high and low frequency amplification simultaneously, equivalent therefore to three valves) with reaction so adjusted that oscillation cannot take place, tuned anode, variometer tuning, and a strength switch for adjusting the loudness of

NO. 2848 , voL. I I 3$]$ 
the telephones by a resistance. There is also a rejector circuit for tuning out near stations (acting as a wave filter). The valves are of the dull emitter type, with their filaments in series on the same battery that supplies the filaments of the two further power amplifier valves, the equipment for which is on the lower panel. A strength switch is here provided for the loud speaker, and a convenient switch for using one, two, three, or four valves at will and connecting or disconnecting the loud speaker by moving the knob in and out. This is so arranged that the head telephones cannot be connected to the higher numbers of valves, to avoid risk of damage. A set of this kind supplied to the
President of Poland is said to pick up in that country all the British broadcasting stations.

A certain amount of miscellaneous scientific apparatus is shown in the British Government Pavilion in sections organised by the National Physical Laboratory, the Royal Society, the Science Museum, South Kensington, and the Royal Institution. Those of electrical interest include some early types of incandescent lamps, historic apparatus used by Faraday, a collection of early Crookes' and X-ray tubes, mass spectrum apparatus of Dr. F. W. Aston, and Prof. C. G. Barkla's apparatus by which the polarisation of scattered $\mathrm{X}$-rays and characteristic X-rays were discovered.

\section{Exhibition of the Royal Academy of Arts, I924.}

\section{$\mathrm{T}$} $\mathrm{E}$ late Mr. Clutton Brock claimed with eloquent and reasoned insistence that, for its perfection, man's intellectual development needs to be duly tinged with æsthetics, the love of beauty for its own sake, as well as with philosophy, the science of conduct, on an equal footing with the love of truth; and his doctrine is supported by other apostles of the new Trinity of truth, goodness, and beauty. Assuming that a modicum of philosophy is the common heritage of them all, we may agree that the denizens of Burlington House have need of one another, and that the student of science is an imperfect creature unless he has a love of beauty for its own sake, which it is the first duty of the Royal Academy to expound and encourage. It is, indeed, not difficult to agree. Scientific discoveries differentiate themselves in ways other than the mere sum and substance of the improvement of natural knowledge. Some expositions of discovery are really beautiful, others are really not.

For good or ill, there is nothing on the scientific side that exactly corresponds with the annual exhibition of the Royal Academy. Artists are not exactly invited once a year to come and look, and then say what they think, from the point of view of beauty, of our exposition of science. There would be something worth saying if they were ; we might at least learn something about what illustrations ought to be and save thoughtful readers untold worries.

This year's academy comprises 674 paintings in oil, $\mathrm{I} 85$ in water colour, $\mathrm{I} 52$ miniature paintings, I4I drawings and engravings, 196 architectural drawings, and 215 sculptures - an extensive expression of the natural demand for the cultivation of the sense and power of beauty. And as one passes through the rooms and is faced with the question, "Well, what do you think of it all ?" one is tempted to speculate on the canons or motives which guide the artist's mind in the exercise of his function of being inspired by and in turn inspiring his environment.

Perhaps the most prominent motive is the aid to the memory of the beautiful, which, at the best, is changing and evanescent, and which the layman might never realise at all without the artist's aid. To judge by the pictures of the year the human "form divine " clothed in various ways is the most appealing feature of their environment for the artists of the twentieth century, sometimes recalling Solomon in all his glory and sometimes with nothing on.

The appeal is more on the biological and psycho- logical side than the physical. The studies of inanimate nature are less numerous and less striking than those of men and women, and animals, tame or wild. Even the portraits of the scientific bear out this suggestion. To set against those of Sir Donald MacAlister, Bt., of Tarbert (No. r87), by George Henry, R.A. ; Lieut.-Gen. Sir John Goodwin, K.C.B., F.R.C.S. (2I7), by Maurice Greiffenhagen, R.A.; Sir Charles Sherrington, G.B.E., P.R.S. (630), by Augustus E. John, A.R.A.; and Prof. A. C. Seward, F.R.S., Master of Downing College (632), by William O. Hutchison, there are, it is true, portraits of Sir J. J. Thomson, O.M., F.R.S. (34I), by René de I'Hôpital, and Sir Maurice Fitzmaurice, C.M.G., F.R.S. (305), for the Institution of Civil Engineers, by George Harcourt, A.R.A.; but they are two against four, and the Master of Trinity seems a little more "cornered" than one is accustomed to. To get a good view of the president of the Royal Society it is well to choose a bright day, otherwise the canon, ars est celare artem, may seem to have been rather roughly disregarded by Mr. John. The contrast of " art" between that and its near neighbour the Master of Downing is almost painful.

Passing from the variously adorned to the unadorned, bathing scenes are numerous and occasionally curious (22), and perhaps the student of biological statistics might find on investigation that the correlation between the absence of adornment and bobbed hair has actually changed its sign from the negative to the positive since Adam and Eve left the Garden of Eden, or even since Tennyson "waited for the train at Coventry."

Not many of the landscapes are very impressive. For a layman the best are those of Adrian Stokes, R.A., Cypress and Olive (I43), San Vigilio (212), A Ring of Cypresses (54); Sir D. Murray, R.A., pictures of Wells $(272,493,464)$, and those of the neighbourhood of London by Mr. W. L. Wyllie, R.A. (333 and 587 ), to which is added one like unto them, (I 7 I) Scarborough Castle. Artists apparently still insist on going to medieval painters instead of to Nature for their clouds, except Mr. E. L. Lawrenson $(16,26 \mathrm{r}, 627)$, who is adventurous but not quite happy with the colouring of his cloud-margins. There is a tendency among the landscapes to bury the scene in a murky atmosphere, not at all void, but without form. Mr. Wyllie finds the London atmosphere convenient for that, and Mr. Oliver Hall, A.R.A. (I24, 242), finds the same kind of dingy sky in Dorset and the Lake District. It will be rather unfortunate if the artists make the murky atmosphere of cities a fashionable form

$$
\text { NO. } 2848 \text {, vOL. I I } 3]
$$

